NBS

PUBLICATIONS

A 11102 637421

NAT'L INST OF STANDARDS \& TECH R.I.C.

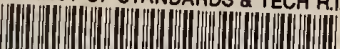

A11

NBS TECHNICAL NOTE 1232

Robinson A11102637421

\title{
A Description of NBS Calibration Services in Mechanical Vibration and Shock
}

D. C. Robinson, M. R. Serbyn, and B. F. Payne

$-A C$

100

.105753

$\# 1232$

1987

C. 2 
he National Bureau of Standards' was established by an act of Congress on March 3, 1901. The Bureau's overall goal is to strengthen and advance the nation's science and technology and facilitate their effective application for public benefit. To this end, the Bureau conducts research and provides: (1) a basis for the nation's physical measurement system, (2) scientific and technological services for industry and government, (3) a technical basis for equity in trade, and (4) technical services to promote public safety. The Bureau's technical work is performed by the National Measurement Laboratory, the National Engineering Laboratory, the Institute for Computer Sciences and Technology, and the Institute for Materials Science and Engineering.

\section{The National Measurement Laboratory}

Provides the national system of physical and chemical measurement; coordinates the system with measurement systems of other nations and furnishes essential services leading to accurate and uniform physical and chemical measurement throughout the Nation's scientific community, industry, and commerce; provides advisory and research services to other Government agencies; conducts physical and chemical research; develops, produces, and distributes Standard Reference Materials; and provides caiibration services. The Laboratory consists of the following centers:
- Basic Standards ${ }^{2}$

- Radiation Research

- Chemical Physics

- Analytical Chemistry

\section{The National Engineering Laboratory}

Provides technology and technical services to the public and private sectors to address national needs and to solve national problems; conducts research in engineering and applied science in support of these efforts; builds and maintains competence in the necessary disciplines required to carry out this research and technical service; develops engineering data and measurement capabilities; provides engineering measurement traceability services; develops test methods and proposes engineering standards and code changes; develops and proposes new engineering practices; and develops and improves mechanisms to transfer results of its research to the ultimate user. The Laboratory consists of the following centers:
- Applied Mathematics

- Electronics and Electrical Engineering ${ }^{2}$

- Manufacturing Engineering

- Building Technology

- Fire Research

- Chemical Engineering ${ }^{2}$

\section{The Institute for Computer Sciences and Technology}

Conducts research and provides scientific and technical services to aid Federal agencies in the selection, acquisition, application, and use of computer technology to improve effectiveness and economy in Government operations in accordance with Public Law 89-306 (40 U.S.C. 759), relevant Executive Orders, and other directives; carries out this mission by managing the Federal Information Processing Standards Program, developing Federal ADP standards guidelines, and managing Federal participation in ADP voluntary standardization activities; provides scientific and technological advisory services and assistance to Federal agencies; and provides the technical foundation for computer-related policies of the Federal Government. The Institute consists of the following centers:
- Programming Science and Technology

- Computer Systems Engineering

\section{The Institute for Materials Science and Engineering}

Conducts research and provides measurements, data, standards, reference materials, quantitative understanding and other technical information fundamental to the processing, structure, properties and performance of materials; addresses the scientific basis for new advanced materials technologies; plans research around cross-country scientific themes such as nondestructive evaluation and phase diagram development; oversees Bureau-wide technical programs in nuclear reactor radiation research and nondestructive evaluation; and broadly disseminates generic technical information resulting from its programs. The Institute consists of the following Divisions:
- Ceramics

- Fracture and Deformation ${ }^{3}$

- Polymers

- Metallurgy

- Reactor Radiation 


\section{NBS TECHNICAL NOTE 1232}

\section{A Description of NBS Calibration Services in Mechanical Vibration and Shock}

D.C. Robinson

M.R. Serbyn

B.F. Payne

Acoustic Measurements Group Automated Production Technology Division

National Bureau of Standards

Gaithersburg, MD 20899

February 1987

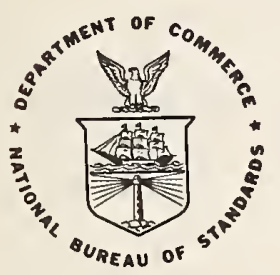

U.S. Department of Commerce

Malcolm Baldrige, Secretary

National Bureau of Standards

Ernest Ambler, Director 
National Bureau of Standards Technical Note 1232

Natl. Bur. Stand. (U.S.), Tech. Note 1232, 26 pages (Feb. 1987) CODEN: NBTNAE

U.S. GOVERNMENT PRINTING OFFICE

WASHINGTON: 1987

For sale by the Superintendent of Documents, U.S. Government Printing Office, Washington DC 20402 


\section{INTRODUCTION}

2. COMPARISON CALIBRATION OF ACCELEROMETERS

2.1 Description of Service

2.2 Low-Frequency Range

2.2.1 General Characteristics of Exciters

2.2.2 Calibration Procedures

2.3 Mid-Frequency Range

2.3.1 General Characteristics of Exciters

2.2.3 Automated Comparison Calibration

2.4 High-Frequency Range

2.4.1 General Characteristics of Exciters

2.4.2 Automated Comparison Calibration

2.5 Special Test of Shock Transducers

3. ABSOLUTE CALIBRATION OF REFERENCE EXCITERS AND ACCELEROMETERS

3.1 Absolute versus Comparison Calibration Service

3.2 Ronchi Rulings Methods

3.3 Fringe-Counting Interferometer

3.4 Reciprocity Calibration

3.5 Automated Fringe-Disappearance Interferometer

3.6 Laser Interferometer using the J - Null Method

3.7 Folded-Beam Interferometer

4. REFERENCES 



\section{INTRODUCTION}

There are two principal categories of measurement used in the calibration of accelerometers and reference exciters at the National Bureau of Standards: comparison and absolute. When the calibration factor is obtained directly from a measurement of quantities which form the base units of a system of units, the calibration is called absolute [1]. The comparison method involves simultaneous measurement of the outputs of the transducer under test and a reference transducer of known and stable characteristics, with both devices subject to the same excitation. The comparison method has been implemented by constructing a vibration exciter with a built-in or attached transducer and a space for mounting an accelerometer to be tested. A test accelerometer can be readily calibrated by direct comparison of its voltage to that of a standard. The comparison method is very simple and relatively inexpensive, compared to the absolute methods of calibration, which can be very time consuming. This survey document describes the methods of calibrating vibration pickups by comparison with NBS standards, including a special shock calibration service, and absolute methods used primarily in the calibration of the reference standards.

A summary is given of the various calibration procedures, beginning with the comparison calibration procedures using electrodynamic, air-bearing, and piezoelectric exciters which cover the low, mid, and high-frequency ranges, respectively. A shock calibration service which employs analog-to-digital converters and fast Fourier transform analysis to calibrate a test accelerometer in terms of a reference accelerometer is then described. The last section describes the absolute calibration procedures which are primarily used to calibrate the reference exciters and accelerometers.

\section{COMPARISON CALIBRATION OF ACCELEROMETERS}

\subsection{Description of Service}

Once the standard accelerometer has been calibrated by one of the absolute methods described later, smoothing is performed on the experimental data. The resulting frequency response function is the sensitivity of the standard. A test accelerometer is readily calibrated by mounting it on the exciter and obtaining the voltage ratio of the test and standard accelerometers. The sensitivity of the test accelerometer is given by

$$
S_{\text {test }}=\frac{E_{\text {test }}}{E_{\text {standard }}} \quad S_{\text {standard }}
$$


where:

$$
\begin{aligned}
& \mathrm{E}_{\text {test }} \quad=\text { voltage output of the test accelerometer } \\
& \mathrm{E}_{\text {standard }} \quad=\text { voltage output of the standard accelerometer, and } \\
& \mathrm{S}_{\text {standard }} \quad=\text { sensitivity of the standard accelerometer. }
\end{aligned}
$$

Comparison calibrations of accelerometers and other vibration pickups are performed routinely in a permanent facility. Both the single-ended and the back-to-back type transfer standards are accepted. The measurements are performed under the environmental conditions recommended by the pertinent ISO standard [2], namely at a temperature of $23 \pm 3^{\circ} \mathrm{C}$ and a relative humidity of $50 \pm 20$ percent. The test procedures are automated and computer controlled.

The pickups are normally calibrated at discrete frequencies in the range 10$10,000 \mathrm{~Hz}$, and the normal test accelerations are 2,5 , and $10 \mathrm{~g}$, where $\mathrm{g}$ is the standard acceleration of free fall, equal to $9.80665 \mathrm{~m} / \mathrm{s} / \mathrm{s}$. The measurand is the sensitivity, whose magnitude is also called calibration factor, of the vibration pickup. It is defined as the ratio of an electrical output quantity to a mechanical input quantity. For example, the calibration of an accelerometer may be reported as charge sensitivity in $\mathrm{pC}$ per $\mathrm{g}$ for the pickup alone or as voltage sensitivity in $\mathrm{mV}$ per $\mathrm{g}$ for the pickup-amplifier combination. (For non-American users the preferred units would be $\mathrm{pC}$ per $\mathrm{m} / \mathrm{s} / \mathrm{s}$.) Because sensitivity is a ratio of two phasor quantities, it contains a phase component in addition to the magnitude. Phase calibration is also provided, upon request, and is expressed in degrees.

The NBS standards to which comparison is made are carefully maintained and periodically recalibrated by absolute methods. Transfer of accuracy is assured by established measurement procedures which are automated and computercontrolled. The uncertainty of a comparison calibration varies from \pm 1 percent to \pm 3 percent, depending on the frequency range and the particular test requested [3]. This information is provided to the user as part of the calibration report. User requirements which do not fall into the categories listed in Ref. 3 can usually be met by a special test performed at cost by prearrangement. A summary of the calibration methods is shown in Table 1.

The exciters used for the comparison method are calibrated by an absolute method based on optical interferometry or the reciprocity principle (or both). The reference transducer is usually an accelerometer, although it can be a coil moving in a magnetic field. Since no single vibration exciter or calibration procedure is adequate for the frequency range of 2 to $15,000 \mathrm{~Hz}$, several options for presenting the particular material of this Section exist. We have chosen to do it on the basis of frequency range. 


\begin{tabular}{|c|c|c|c|c|}
\hline & Rat & & Estimated & \\
\hline Calibrator & $\begin{array}{l}\text { Acceleration } \\
(\mathrm{g})\end{array}$ & $\begin{array}{l}\text { Frequency } \\
(\mathrm{Hz})\end{array}$ & $\begin{array}{l}\text { Uncertainty* } \\
(\%)\end{array}$ & Method \\
\hline
\end{tabular}

\begin{tabular}{|c|c|c|}
\hline Low- & $0.2-2.5$ & $2-4$ \\
\hline Frequency & & $5-100$ \\
\hline
\end{tabular}

\begin{tabular}{|c|c|c|}
\hline Air- & $2-10$ & $<50$ \\
\hline Bearing & & $50-2,000$ \\
\hline \multirow[t]{2}{*}{ Exciter } & & $2,500-3,000$ \\
\hline & & $3,500-10,000$ \\
\hline $\begin{array}{l}\text { Piezo- } \\
\text { Electric }\end{array}$ & $2-100$ & $\begin{array}{l}3,000-10,000 \\
11,000-15,000\end{array}$ \\
\hline
\end{tabular}

Comparison to reference

standard calibrated by

an optical ruling (2-10

$\mathrm{Hz}$ ) or laser interfero-

meter fringe counting

$(2-100 \mathrm{~Hz})$ method.

Comparison to reference

standard calibrated by

reciprocity $(10 \mathrm{~Hz}-10 \mathrm{kHz})$

and checked by interfero-

metric methods.

Comparison to reference standard calibrated by

a laser fringe-disappearance interferometer.

Shock

$50-5,000$

$10-10,000$

$\pm 5$

Exciter

"Back-to-back" comparison to a standard calibrated using continous sinewave excitation. Shock pulses are "halfsine" having pulses widths from $40-0.2 \mathrm{~ms}$.

${ }^{*}$ The uncertainty is a statement of possible random and systematic errors from all known sources expressed as a root mean square value. 


\subsubsection{General Characteristics of Exciters}

An electrodynamic vibration exciter has been developed to calibrate accelerometers at low frequencies down to $2 \mathrm{~Hz}$. This work has provided the National Bureau of Standards with the capability of covering a frequency range of 2 to $100 \mathrm{~Hz}$. The maximum acceleration amplitude is $2.5 \mathrm{~g}$ peak or as limited by a displacement of approximately $4.5 \mathrm{~cm}$ double amplitude. The attainable amplitude and accuracy of accelerometer calibration on this exciter is limited by transducer size, weight, geometry, and vibration sensitivity. Examples of the types of pickups which can be calibrated are servo or force balance, piezoelectric, piezoresistive, and strain gage accelerometers.

The low-frequency vibration exciter, Type LF-1, is shown in Fig. 1. It is a variant of the Dimoff Type 200 exciter [4,5], designed for the frequency range $1-100 \mathrm{~Hz}$; in fact, many of the components are identical. Full documentation of this exciter is found in Ref. 6. The motion of such an exciter must have very low waveform distortion and minimal components of motion in all directions other than axial. In addition, the attainable amplitude must be large enough to produce an accelerometer signal that can be accurately measured. The reference accelerometer system consists of a servo accelerometer and amplifier. Absolute calibration of the reference standard is discussed in a later section on the procedures for absolute calibration of the reference exciters.

\subsubsection{Calibration Procedure}

FIGURE 1. LOW FREQUENCY AIR BEARING SHAKER LF-1

The calibration procedure is based on Eq. (1), with the standard consisting of a stable servo accelerometer mounted inside the moving element of the exciter. The chief difficulty in this type of calibration lies in the measurement of the voltage output at low frequencies. The need of the measurement to encompass at least several vibration cycles raises the requirement of stationarity of the signal, while the reduced response of the sensor increases the signal-to-noise ratio. In order to minimize errors, two approaches to measuring voltage have 
been used: a true-rms differential voltmeter and an ac-to-dc converter followed by a dc-to-frequency converter. A fast-response, low-frequency sampling voltmeter, developed at NBS, will soon be tested in this application.

The estimated uncertainty in the measured values of the sensitivity factors for accelerometers calibrated on the low-frequency exciter, by comparison to the internal reference standard, does not exceed \pm 1 percent from 100 to $5 \mathrm{~Hz}$ and \pm 2 percent below $5 \mathrm{~Hz}$. This estimated uncertainty is for an accelerometer having a sensitivity of approximately $1 \mathrm{~V}$ per g. It is also assumed that the accelerometer is suitable for use as a laboratory standard, i.e., it has a high signal-to-noise ratio, miminimal sensitivity to case strain, minimal thermal sensitivity shift, etc. Increases in estimated uncertainity must be made on an individual basis for accelerometers which do not possess the above characteristics.

\subsection{Mid-Frequency Range}

\subsubsection{General Characteristics of Exciters}

The Dimoff air-bearing Type 200 exciter is shown in Fig. 2 and its general characteristics are described in Ref. 4.

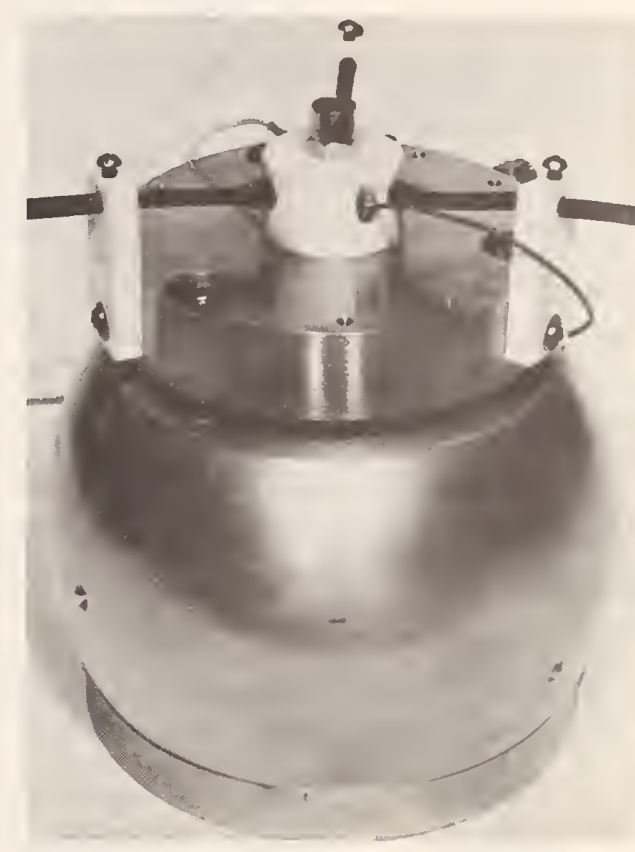

FIGURE 2. DIMOFF AIR BEARING SHAKER TYPE 200

The accelerometer to be calibrated is attached to the calibrator table, and the reference accelerometer is inside the moving element. The armature and the table are as rigid as practical to minimize table bending and to maximize the frequency of the first axial resonance. Air bearings are used to assure low distortion and low transverse motion. Sinusoidal motion is obtained when a sinusoidal current is passed through the drive coil. The present range of calibration is 10 to $10,000 \mathrm{~Hz}$ for comparison calibration using these exciters.

The use of reciprocity calibrated standards for performing routine comparison calibrations is discussed in Ref. 5. Transverse motions of the mounting table for these exciters have been measured using two accelerometers mounted with their principal axes mutually perpendicular to the direction of motion. These and other determinations provide assurance that the transverse acceleration is no greater than 1.5 percent of axial acceleration [7]. Further details of the Dimoff Type 200 exciters which are used in most comparison accelerometer calibrations at NBS are given in Ref. 5. 


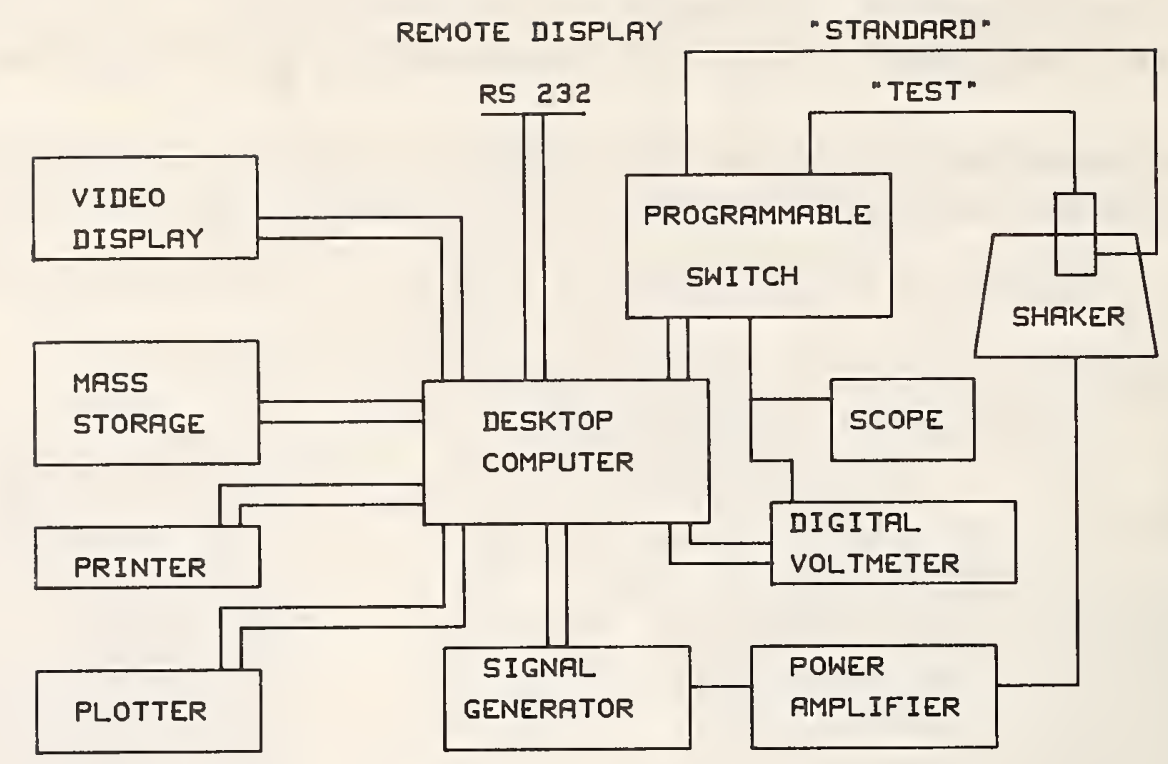

\section{FIGURE 3. COMPONENTS OF AUTOMATED COMPARISON SYSTEM}

\subsubsection{Automated Comparison Calibration}

Figure 3 shows a diagram of the components used in the automated calibration system. Most accelerometer calibrations at NBS are performed by the comparison method using the Dimoff Type 200 exciters. The various methods of absolute calibration of these exciters and their built-in accelerometers are described in Sec. 3. The measurement procedure for the automated calibration system, which applies to both the mid-frequency and high-frequency ranges, can best be explained by reference to the functional diagram of Fig. 3 [5]. The output voltage from a low-distortion programmable signal generator is amplified by a power amplifier and energizes the exciter at a given test frequency and acceleration. The digital voltmeter (DVM) is programmed to read first the voltage output of the standard accelerometer in the exciter

$\left(\mathrm{E}_{\text {standard }}\right)$ and then the voltage output of the test accelerometer $\left(\mathrm{E}_{\text {test }}\right)$. The DVM samples the voltages and they are stored in the computer memory. Typically 25 voltage readings are stored in a sample. These voltages are then averaged and the standard deviation, normally less than 0.1 percent, is computed. The DVM is programmed so that samples which may be affected by spurious signals are discarded. Upon the completion of the data sampling, the sensitivity of the test accelerometer is calculated from Eq. (1). The sensitivity for this test frequency is stored in computer memory and calibrations at the remaining test frequencies and accelerations are performed in the same manner. 
Usually accelerometers are submitted for calibration with an accompanying charge amplifier which converts the charge output of the accelerometer to an ac voltage that can be readily measured on a digital voltmeter. Some users prefer to obtain a calibration of the pickup alone in terms of the charge per unit acceleration ( $\mathrm{pC}$ per $\mathrm{g}$ ). The procedure in this case is to use a NBS charge amplifier of known charge gain and to calibrate this amplifier and accelerometer system in the usual manner. The final step is to divide the resulting calibration factors by the charge gain of the NBS amplifier and thus obtain the required charge sensitivity. The procedure for measuring the charge gain of the charge amplifier is given in Ref. 5.

The last stage of the calibration process consists of data reduction and reporting, which are also done by the computer. The data collected in the computer memory consist of: (1) test frequency, (2) voltage output from the NBS standard, (3) voltage output from the test accelerometer. Two exciters are used, and each accelerometer is calibrated twice on each exciter, for a total of four sets of calibration data. The computer program averages the four sets and rounds the average sensitivity to reflect the accuracy of the calibration in the number of digits reported. At the present time, the automated calibration data are given in NBS Reports of Calibration over a frequency range of $10 \mathrm{~Hz}$ to $10,000 \mathrm{~Hz}$. The automated comparison system is used also for double-ended, or "piggy-back" accelerometers over this frequency range. A calibrated standard accelerometer is mounted on top of the piggy-back accelerometer to be calibrated, and a comparison calibration is performed on the piggy-back accelerometer. Additional information on the test report and the assessment of uncertainty and quality control are given in Ref. 5.

\subsection{High-Frequency Range}

\subsubsection{General Characteristics of Exciters}

Most methods for the accurate calibration of vibration pickups require sinusoidal motion with low distortion along a single axis over a wide range of frequencies. The air-bearing exciters described above satisfy these requirements extremely well at frequencies up to several kilohertz. At higher frequencies, when transverse motion of the moving element becomes objectionable, piezoelectric exciters can be used to generate uniaxial motion over a wide frequency range. A stagger-tuning method has been developed for building such exciters which have low waveform distortion, minimal errors due to transverse motion, and a relatively good approximation to flat frequency response over a wide range [8]. The NBS piezoelectric exciters can be used over a frequency range from $3,000 \mathrm{~Hz}$ to $30,000 \mathrm{~Hz}$, but comparison calibrations are routinely requested only over the range from 3,000 to $15,000 \mathrm{~Hz}$. A simplified representation of a piezoelectric exciter is shown in Fig. 4. The table material must be sufficiently stiff that the mechanical impedance of that portion of the surface affected by the pickup attachment at any given frequency will be much greater than the impedance of the pickup attachment. 
The base must also have a sufficiently high mechanical impedance so that the behavior of the piezoelectric exciter does not vary unduly with different supporting structures. The dimensions of the base transverse to the long axis

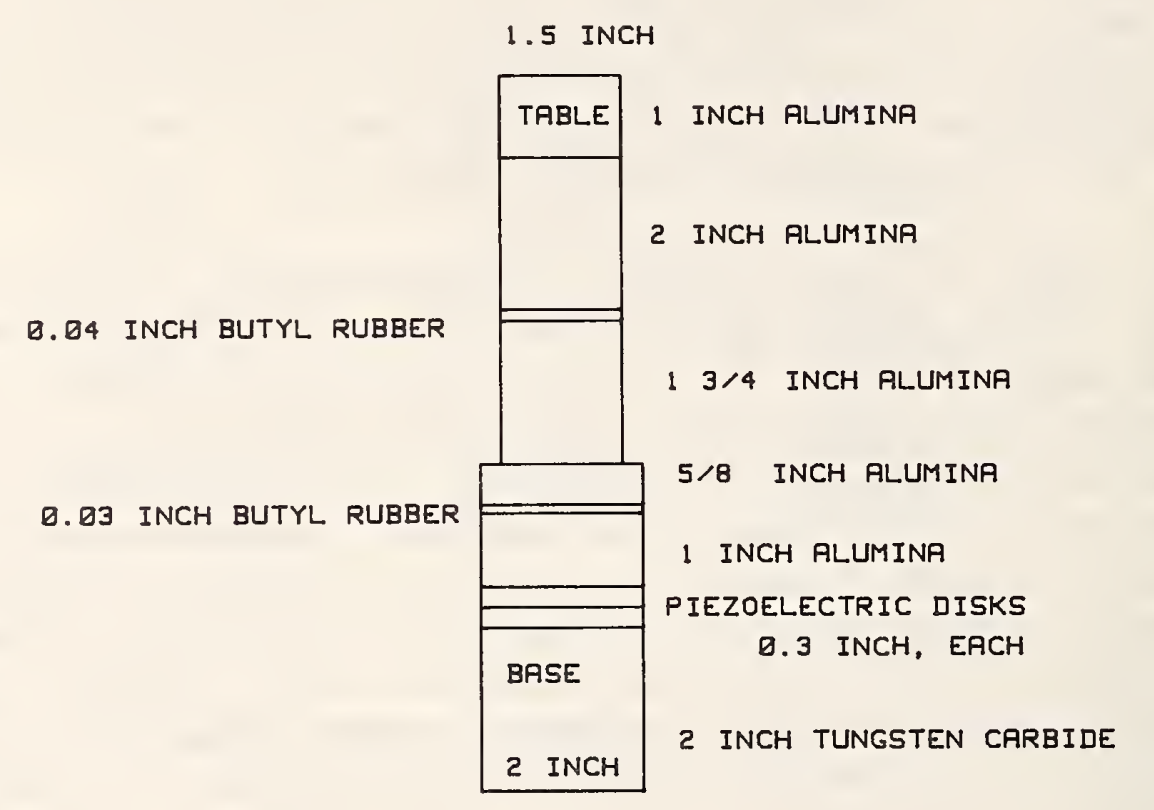

FIGURE 4. PIEZOELECTRIC VIBRATION EXCITER

must be small relative to the wave length of sound in the material in order to reduce transverse motion, but sufficiently large to provide adequate flexural rigidity. Further details of the piezoelectric exciter characteristics are given in Ref. 8.

\subsubsection{Automated Comparison Calibration}

The measurement procedure for the automated calibration system is the same as for the mid-frequency method previously described, except for the exciters. Most comparison calibrations are performed on the Dimoff vibration exciters, which have a usable frequency range of $10 \mathrm{~Hz}$ to $10,000 \mathrm{~Hz}$. There is gradually increasing magnitude of transverse vibration at the higher frequencies, which accounts for reduced accuracy in that frequency range. To some users this 1 percent increase in uncertainty is unacceptable. Others require a calibration at frequencies beyond $10 \mathrm{kHz}$. In those cases a piezoelectric exciter is used with a standard accelerometer that has been calibrated interferometrically. This approach to maintaining a 2 percent uncertainty up to $10,000 \mathrm{~Hz}$ has been used at NBS since 1981 [9]. If the accelerometer to be calibrated is of the 
single-ended type, the standard must be of the back-to-back type, and vice versa. The rest of the measurement system and procedure remain unchanged $[10,11]$.

\subsection{Special Test of Shock Transducers}

A new shock accelerometer measurement service is being offered by the National Bureau of Standards. A computer-controlled waveform analysis and signal processing device, employing Fast Fourier Transform techniques to transform time-domain data into frequency-domain data, is used to determine the frequency- dependent sensitivity in both magnitude and phase of an accelerometer. The time-domain comparison also yields the values of peak acceleration as well as the velocity obtained by integrating the acceleration-versus-time curve. Comparison shock calibrations, in the frequency domain, greatly simplify the measurements necessary to perform calibrations throughout an acceleration range from 50 to $5,000 \mathrm{~g}$. Generally, this is accomplished with the use of "half-sine" pulses having pulse widths from about $40 \mathrm{~ms}$ to $0.2 \mathrm{~ms}$.

The laboratory equipment consists of four main items: a mechanical shockgenerating machine, two accelerometers, a data capture and analysis system, and a computer for data storage and manipulation. These items provide a means for transient-data generation, data collection and reduction, and calibration of the test accelerometers versus a reference standard.

The reference system consists of a piezoelectric accelerometer and a matched solid-state charge amplifier. Because the accelerometer is of the "piggy-back" configuration, other test accelerometers can be directly mounted to its top. This permits calibration by the "back-to-back" comparison method, where the electrical outputs of the reference accelerometer and test accelerometer are compared. The accuracy of this method is directly dependent on the accuracy of the calibrated reference.

Table 2 - Test Accelerations and Pulse Widths for Special Shock Calibration Service

Nominal Peak Acceleration

(g)

50

100

500

1000

2000

5000
Average Pulse Width

(ms)

6

4

2

1

0.8

0.3 
The nominal peak accelerations $( \pm 10$ percent) and corresponding pulse widths of this measurement service are given in Table 2. The reference accelerometer is linear to within $0.5 \%$ over the range of acceleration amplitudes given in the table.

\section{ABSOLUTE CALIBRATION OF REFERENCE EXCITERS AND ACCELEROMETERS}

\subsection{Absolute versus Comparison Calibration Service}

The approach to vibration calibration at NBS can be summarized as follows. A high-quality exciter with a very stable internal accelerometer is designed and constructed. These standards are calibrated by absolute methods, and a smooth curve is fitted to the experimental data. These results, appropriately weighted and plotted as a function of frequency, yield the calibration factors for the NBS standards.

Considerable effort has been devoted to obtaining the best possible calibration for the standard exciters and accelerometers since most calibrations issued by NBS will be based on these standards. A long history of performance has been maintained on the NBS standards to provide enough data for good statistical analyses. The error associated with transferring a calibration from an NBS standard to a test accelerometer is thereby minimized. The calibration of the standards is periodically checked, using absolute methods. The inherent stability of these standards, together with the use of a controlled environment in which they are stored and used, give added confidence in the uncertainty statements for each test. Consequently, a calibration by comparison is not to be considered inferior to an absolute calibration: as has already been suggested, the distinction between the two is not on the basis of accuracy.

If absolute methods were used on each customer accelerometer tested, the cost would be unjustifiably high for most users. Thus, the comparison method, which is simple and relatively inexpensive, is requested almost exclusively. The absolute methods are normally reserved for the calibration of NBS standards. In the mid-frequency range, a method based on the reciprocity principle has established itself alongside several interferometric methods; for measurements at low or high frequencies, interferometric techniques are more reliable.

The absolute methods described below are neither competing nor equivalent but, rather, complementary. Their ranges of applicability and special features will be pointed out. In general, it should be noted that, with the exception of the Ronchi-grid and reciprocity methods, they are adaptations of the Michelson interferometer to particular dynamic problems. 


\subsection{Ronchi Rulings Method}

Two, methods for calibrating electrodynamic low-frequency vibration exciters are the optical ruling and interferometric fringe counting methods. The first method, which is no longer used routinely, makes use of two optical rulings (Ronchi grids) to measure the amplitude of vibrational displacement.

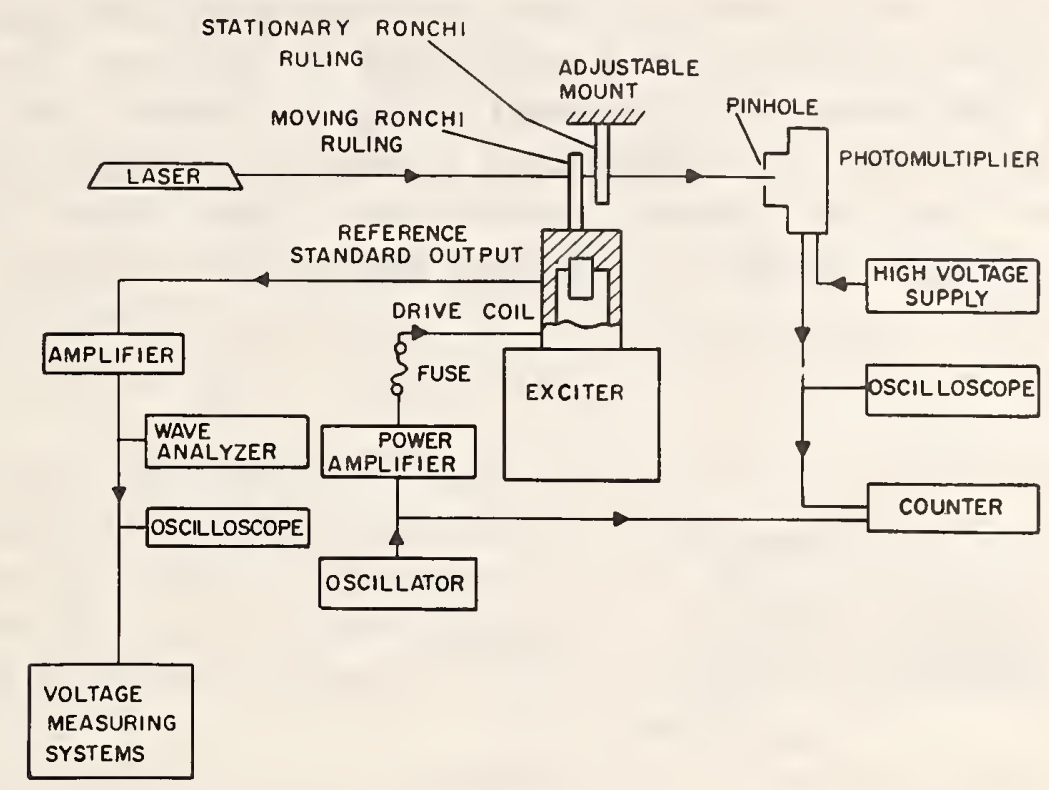

\section{FIGURE 5. RONCHI RULING CALIBRATION SYSTEM}

A diagram of this calibration system is given in Fig. 5. The two Ronchi rulings are mounted so that the ruled lines and the ruled surfaces are parallel. The exciter vibrates the moving ruling with respect to the stationary ruling, causing the intensity of the laser beam entering the photomultiplier tube to be modulated. For each displacement equal to the width of the line-pair, an electrical pulse is generated by the photomultiplier. (A line pair is one transparent line and one opaque line on a Ronchi ruling.) The number of pulses per vibration cycle is directly proportional to the displacement amplitude. Assuming sinusoidal motion, the acceleration, a, is calculated from

$$
\mathrm{a}=(2 \pi \mathrm{f})^{2} \mathrm{~d}=\pi^{2} \mathrm{f}^{2} v / \mathrm{n}
$$

where $\mathrm{d}=$ displacement amplitude,

$\mathrm{f}=$ frequency of vibration,

$\nu=$ number of pulses per vibration cycle, and

$\mathrm{n}=$ number of line pairs per unit length on the Ronchi rulings.

The uncertainty associated with this method was determined as follows. Before being mounted inside the moving element of the exciter, the reference standard (servo accelerometer) was calibrated several times. Static calibration was 
performed on a tilt table [12]. The uncertainty of the static value of the sensitivity was \pm 0.1 percent. The reference standard was also checked against another NBS vibration standard, described in Section 2.3.1, from 10 to $50 \mathrm{~Hz}$. The agreement was within 2 percent.

\subsection{Fringe-Counting Interferometer}

A diagram of the interferometric fringe counting calibration system is given in Fig. 6. The He-Ne laser light has a wavelength of $632.8 \mathrm{~nm}$. The configuration is basically a Michelson interferometer using a corner cube retro-reflector mounted on the exciter. The photo-diode generates an electrical pulse for each $\lambda / 2$ displacement and the counter records one fringe count. The number of pulses per vibration cycle is directly proportional to the displacement amplitude.

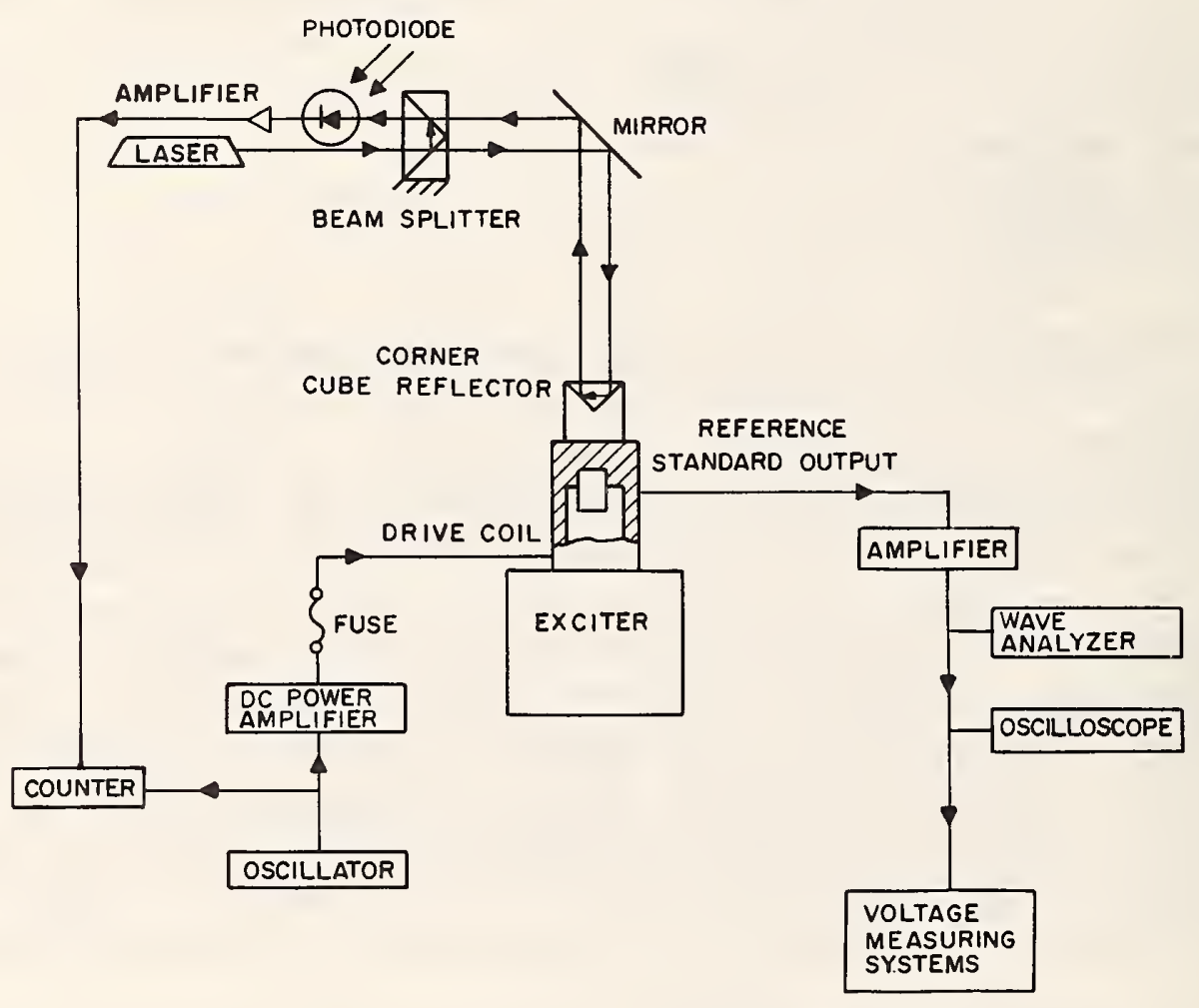

FIGURE 6. FRINGE COUNTING INTERFEROMETER

The acceleration is calculated from 


$$
a=(2 \pi f)^{2} d=\lambda \nu \pi^{2} f^{2} / 2
$$

where $\lambda=$ wavelength of the laser light, in meters,

$\nu=$ number of pulses per vibration cycle, and the other symbols have the previously-defined meanings.

A discussion of estimated errors in the fringe-counting laser interferometer method is given in Ref. 6. Typically, the root-mean-square error for this method is \pm 0.5 percent.

\subsection{Reciprocity Calibration}

The reciprocity calibration method is used to calibrate vibration exciters equipped with a velocity coil or an accelerometer. This method is based on measurements of voltage ratio, resistance, frequency, and mass.

The Bouche-Levy reciprocity calibration method consists of two experiments: (1) measurement of transfer admittance between the driving coil and the reference accelerometer, and (2) measurement of the voltage ratio of the reference accelerometer and the open-circuited driving coil of the vibration exciter when the latter is driven mechanically by an external shaker [13-17].

In both voltage-ratio and transfer-admittance measurements, the static value of the vertical position of the coil in the gap of the magnet is critical because of the limited distance over which the magnetic field is uniform. It is important to keep this position constant throughout the calibration procedure. For this reason, an optical detector and position control are incorporated into the calibration system. A control unit is attached to a dc motor which controls the vertical position of the moving element. Once a position is selected, the control unit will keep this position constant. This greatly improves repeatability of data and provides for ease of operation.

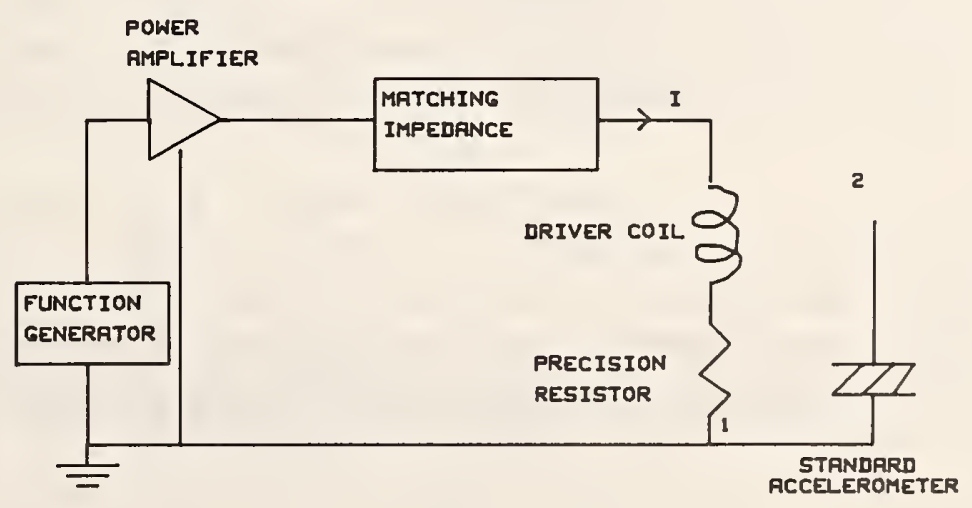

FIGURE 7. CONNECTIONS FOR TRANSFER-ADMITTANCE IN THE RECIPROCITY EXPERIMENTS 
The first experiment consists of measuring the electrical transfer admittance using the circuit of Fig. 7. The relationship defining this transfer admittance is

$$
\mathrm{Y}=\mathbb{I} / \mathrm{E}_{12}
$$

where

$\mathbf{Y}=$ transfer admittance

$\mathrm{E}_{12}=$ voltage generated in the standard accelerometer and amplifier,

$I^{1}=$ current in the driver coil, and the bold letters denote phasor (complex) quantities.

The current is determined by measuring the voltage drop across a standard resistor. The phase, $\phi_{\mathbf{Y}}$, of $\mathbf{Y}$ is measured with a phase meter having an uncertainty of $\pm 0.1 \mathrm{deg}$ or better.

Transfer admittance measurements are made with a series of masses attached, one at a time, to the table of the exciter. Also, a zero-load transfer admittance measurement is made before and after attaching each mass. This zero-load measurement is denoted by $\mathbf{Y}_{0}$. Using the measured values of $\mathbf{Y}$, and $Y_{0}$, graphs of the real and imaginary values of the ratio

$$
T_{n}=M_{n} /\left(Y-Y_{0}\right)
$$

are plotted versus $M_{n}$ for each frequency, where $M_{n}$ are the values of mass attached to the table. The zero intercepts, $\mathrm{J}_{\mathrm{i}}$ and $\mathrm{J}_{\mathrm{r}}$, of the resulting nominally straight lines and their slopes, $\mathrm{Q}_{\mathrm{i}}$ and $\mathrm{Q}_{\mathrm{r}}$, are computed by a weighted least-squares method [16]. The values of $Y_{o}$ used in the calculations are obtained by averaging the values of the $Y_{o}$ measurements before and after each measurement of $\mathbf{Y}$ using different masses. These computed values are used in determining the sensitivity of the standard.

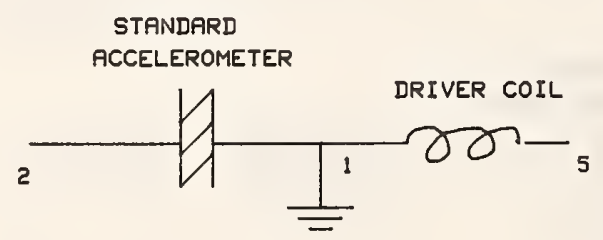

FIGURE 8. CONNECTIONS FOR VOLTAGE-RATIO MEASUREMENT IN THE RECIPROCITY EXPERIMENTS

The electrical connections for the second experiment are shown in Fig. 8. The ratio of two voltages is measured while the exciter is driven with an external 
exciter. The voltage ratio is given by

$$
\mathbf{R}=\mathbf{E}_{14} / \mathbf{E}_{15}
$$

where $\mathbf{E}_{14}=$ voltage generated in the standard accelerometer and amplifier, and

$$
\mathrm{E}_{15}=\text { open-circuit voltage in the driving coil. }
$$

After $\mathbf{R}, J_{r}, J_{i}, Q_{r}$ and $Q_{i}$ have been determined for a number of frequencies, $f$, the sensitivity of the exciter is calculated using the relationships (given in Refs. 13-15):

$$
\mathbf{S}=\left(\frac{\mathbf{R ~ J}}{\mathrm{j} 2 \pi \mathrm{f}}\right)^{1 / 2} \cdot\left(1+\frac{\mathbf{M} \mathbf{Q}}{\mathbf{J}}\right),
$$

where $\mathrm{j}=$ the unit imaginary vector,

$$
\begin{aligned}
& \mathbf{J}=\mathrm{J}_{\mathbf{r}}+j J_{\mathrm{i}}, \\
& \mathbf{Q}=\mathrm{Q}_{\mathbf{r}}+j \mathbf{Q}_{\mathrm{i}} \text {, and } \\
& \mathbf{M}=\mathbf{J}\left(\mathbf{Y}-\mathbf{Y}_{\mathrm{o}}\right) /\left(1-\mathbf{Q}\left(\mathbf{Y}-\mathbf{Y}_{\mathrm{o}}\right)\right)
\end{aligned}
$$

The sensitivity of the exciter is, therefore, determined from the measured quantities $\mathbf{Q}, \mathbf{J}, \mathbf{T}, \mathrm{f}$, and the masses $\mathrm{M}_{\mathrm{n}}$ which are attached to the exciter table. The sensitivity as computed from eq. (7) has the units of $V$ per $\mathrm{m} / \mathrm{s} / \mathrm{s}$ if the values of the measurands are in the SI system. If the masses $M_{n}$ are not in kilograms, appropriate conversion factors must be applied to the quantities $\mathbf{J}, \mathbf{Q}$, and M. A commonly used engineering formula [17], with the mass expressed in pounds and the sensitivity in $\mathrm{mV}$ per $\mathrm{g}$, is

$$
\mathbf{S}=2635(\mathbf{R J} / \mathrm{jf})^{1 / 2},
$$

which assumes that $\mathrm{MQ} / \mathrm{J} \ll 1$, a condition usually satisfied in practice. The use of a computer greatly facilitates the application of the reciprocity calibration process. A desktop computer programmed in BASIC performs the necessary calculations and controls the acquisition of data [15].

Originally stainless steel masses were used, but they limited the usable frequency range to about $5 \mathrm{kHz}$ by resonating at relatively low frequencies. To extend the frequency range, a new set of masses was fabricated of tungsten carbide. The values range from 93 grams to 185 grams; the effects of lower mass values are difficult to resolve. The calibration factors for a 20-gram mass are computed by interpolating between the zero-load and 93-gram-load sensitivities. The surfaces of the masses which attach to the exciter table were ground and lapped flat across their surfaces to within one wave-length of visible light. The surfaces of the exciter tables are also lapped flat. With these changes, reciprocity data can be obtained from $10 \mathrm{~Hz}$ to $10 \mathrm{kHz}$. 
Reference 4 discusses the error analysis for a reciprocity calibration of an air-bearing exciter with a ceramic-moving element. It is unrealistic to assume that all of the errors listed there are correlated, and the square root of the sum of the squares is considered to be a more valid estimate of uncertainty.

It is \pm 0.85 percent.

The frequency range where the reciprocity method has been found to be most accurate is from 100 to $1000 \mathrm{~Hz}$. Below $100 \mathrm{~Hz}$, difficulties in suspension of the moving element in electrodynamic exciters cause cross-axis motion to be difficult to control; in this range, the fringe-counting method has proven to be less vulnerable to the problem. Above 1000 to $2000 \mathrm{~Hz}$ (depending on the exciter) harmonic distortion increases slightly on most exciters, thereby decreasing the accuracy somewhat. Above 1000 to $2000 \mathrm{~Hz}$, the fringedisappearance method and the use of piezoelectric exciters have proven to be the most accurate, apparently due to lower distortion in motion generated by the piezoelectric exciters in this frequency range.

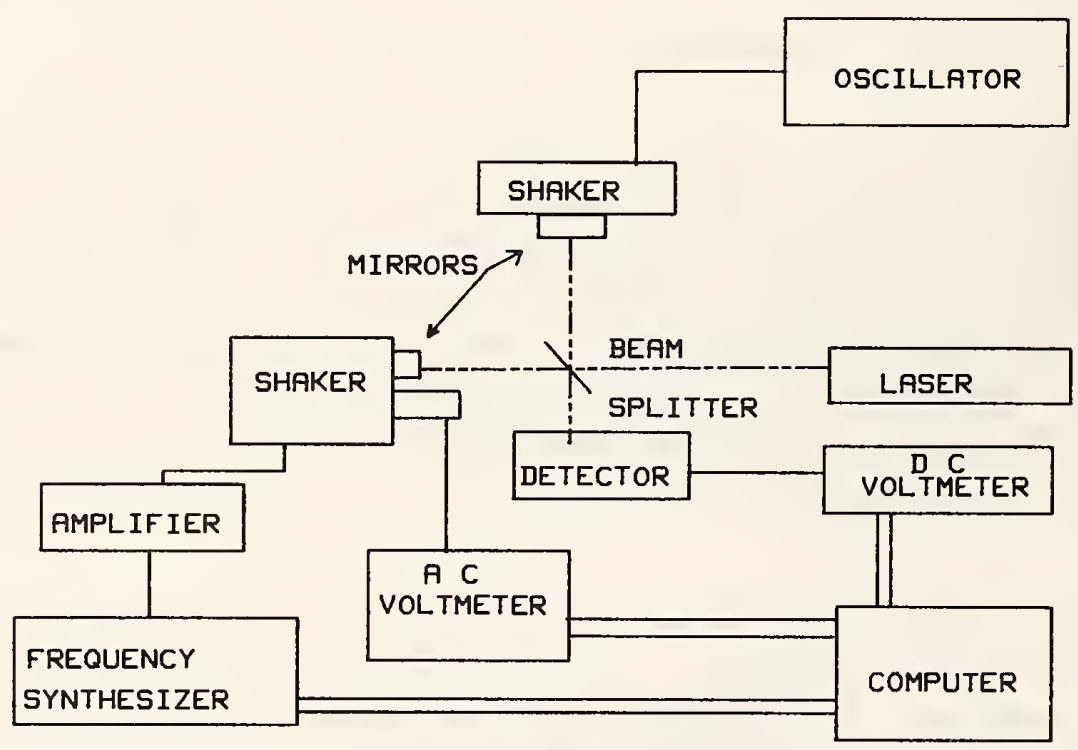

FIGURE 9. OPTICAL MEASUREMENT SYSTEM FOR $121 \mathrm{~nm}$ DISPLACEMENT

\subsection{Automated Fringe-Disappearance Interferometer}

A two-beam Michelson Interferometer has been adapted to measure the magnitude and phase of the sensitivity characterizing a vibration pickup and the system is fully automated with the use of a desktop computer. It was designed to operate in the frequency range 1 to $20 \mathrm{kHz}$, depending on the vibration exciter used. The measurement system is shown schematically in Fig. 9. If the difference of the interferometer optical path length, $2 \Delta=2\left(\mathrm{~L}_{1}-\mathrm{L}_{2}\right)$, 
is modulated by periodically vibrating one of its mirrors, both the amplitude and the phase of this modulation are encoded in the intensity of the light impinging on the photodetector.

The sensitivity of a pickup is defined as the ratio of its electrical output to the mechanical input. In the case of an accelerometer excited by sinusoidal displacement, the magnitude of the sensitivity $\mathbf{S}$ is given by

$$
S=\sqrt{ } 2 E /(2 \pi f)^{2} d
$$

where $\mathrm{f}$ is the frequency, $\mathrm{d}$ is the peak value of the vibratory displacement, and $\mathrm{E}$ is the rms value of the accelerometer output.

Because the value of $d$ in Eq. (9) is determined by the wavelength of the light used, the method is described as absolute, although, in a strict sense, this designation applies only to the displacement measurement.

The basis for the measurement is the following equation for the time-averaged output, $\overline{\mathrm{I}}$, of the photodetector [18]:

$$
\bar{I}=A+B \cos (4 \pi \Delta / \lambda) J_{o}(4 \pi d / \lambda),
$$

where $J_{0}$ is the Bessel function of the first kind of order zero, and $A, B$ are system constants. A low-frequency $(0.1-0.5 \mathrm{~Hz})$ sinusoidal or triangular sweep is applied to the piezoelectric drive of the "fixed" mirror to cause periodic changes in $\Delta$. These changes produce a slowly varying component in the photodetector output which can be followed by a dc voltmeter. To extract the displacement amplitude $d$ from the Bessel function $J_{o}(4 \pi d / \lambda)$, the computer records

$$
\mathrm{M}=\max (\overline{\mathrm{I}})-\min (\overline{\mathrm{I}})
$$

as a function of $\mathrm{E}$ when $\Delta$ is varied.

On substituting the expression for d from Eq. (9) into Eq. (10),

$$
M=2 \mathrm{BJ}_{0}\left(\frac{4 \pi}{\lambda} \frac{\sqrt{ } 2 \mathrm{E}}{\omega^{2} \mathrm{~S}}\right)
$$

Since we are ultimately interested in the root of $J_{0}(4 \pi d / \lambda)$, the Bessel function is replaced by the first two terms of its Taylor expansion about the root, resulting in a linear relationship between $\mathrm{M}$ and $\mathrm{E}$. The E-intercept, therefore, becomes

$$
\mathrm{E}_{\mathrm{M}=0}=2.40482 \quad \omega^{2} \lambda \mathrm{S} /(4 \pi \sqrt{ } 2)
$$


from which $\mathrm{S}$ can be calculated. When the vibration exciter is set precisely at 121.10-nm peak displacement and the acceleration is expressed as a multiple of the standard acceleration of free fall, $\mathrm{g}=9.80665 \mathrm{~m} / \mathrm{s} / \mathrm{s}$, the working formula for sensitivity becomes

$$
\mathrm{S}=\left(2.9008 / \mathrm{f}^{2}\right) \mathrm{E}_{\mathrm{M}=0} \quad \mathrm{mV} \text { per } \mathrm{g},
$$

where $\mathrm{E}$ is the rms value of the accelerometer output in millivolts, and $\mathrm{f}$ is the vibration frequency in kilohertz.

Details of the measurement of the magnitude of $\mathbf{S}$ are given in Ref. 18. That paper also discusses measurement of the phase of $\mathbf{S}$, whose implementation, however, has not yet reached the state of completion sufficient for documentation in this Technical Note.

The first performance test of the measurement system consisted of ascertaining the response of the system components to changes in critical parameter values. It was found that the smallest measurable changes in displacement magnitude was less than 0.1 percent, corresponding to about $0.1 \mathrm{~nm}$. Reference 17 describes a computer-controlled displacement interferometer used to evaluate the performance of piezoelectric exciter designs. Six reflecting mirrors are mounted around the perimeter of the top surface of the exciter, with the center section reserved for transducer mounting. By measuring the sensitivity of the transducer mounted at the center with reference to the $121.1 \mathrm{~nm}$ displacement of each mirror, one can effectively map the motion of the surface of the exciter. The data for the sensitivity values for the six positions for a stagger-tuned exciter described in Ref. 8 have shown a maximum spread of less than 2 percent for any frequency tested.

The noise floor for the very-low-frequency diagnostic signals sampled with the $\mathrm{dc}$ voltmeter is about $1 \mathrm{mV}$. This permits a $60-\mathrm{dB}$ dynamic range in $\mathrm{M}=2 \mathrm{BJ}$ 。 $(4 \pi \mathrm{d} / \lambda)$. In terms of displacement this means that only the band 121.0 to 121.2 $\mathrm{nm}$ is below the noise floor. The sensitivities obtained for a test accelerometer by this method agree with those obtained by reciprocity to within 1 percent over the frequency range $3-10 \mathrm{kHz}$. The frequency range is determined primarily by the characteristics of the vibration exciter. The range of calibration is about 1 to $10 \mathrm{kHz}$ for the routine test range and extends to 30 $\mathrm{kHz}$ for special tests. Although the results have been highly repeatable, at the present time only a 2 percent accuracy is claimed for the magnitude [10].

\subsection{Laser Interferometer Using the $\mathrm{J}_{1}-$ Null Method}

This method, although mathematically similar to fringe disappearance, relies on finding the nulls in the fundamental (ac) component of the signal from the photodetector. The instrumentation is, therefore, quite different, except for the interferometer. Environmental restrictions are more severe. 
The interferometer apparatus is mounted on a granite isolation platform with air springs as isolators. This isolation from floor movement is required to provide the necessary stability in the photodetector signals. Air currents in the room can cause some problems by moving the interferometer components and changing the refractive index of the air. A shield around the beamsplitter and mirrors helps stabilize the interferometer. An active method of stabilization has also been successfully tested [20].

A He-Ne laser is used in this interferometer. The fixed mirror, fabricated of fused silica, is mounted in a holder with micrometer adjustments for rotation and tilt. The fused silica beamsplitter is in a similar mount. The beat-frequency oscillator of a wave analyzer serves as signal source to drive the exciter and also to filter the photodetector signal. The configuration is shown in Fig. 10.

To make amplitude measurements, the following procedure is followed. Before energizing the exciter, the interferometer must be aligned by use of the micrometer adjustments on the beam splitter and fixed-mirror mounts. After energizing the exciter, the translation stage of the photodetector is adjusted for maximum voltage on the analyzer meter. To achieve maximum signal-to-noise ratio, small adjustments in the position and orientation of the photodetector assembly are required.

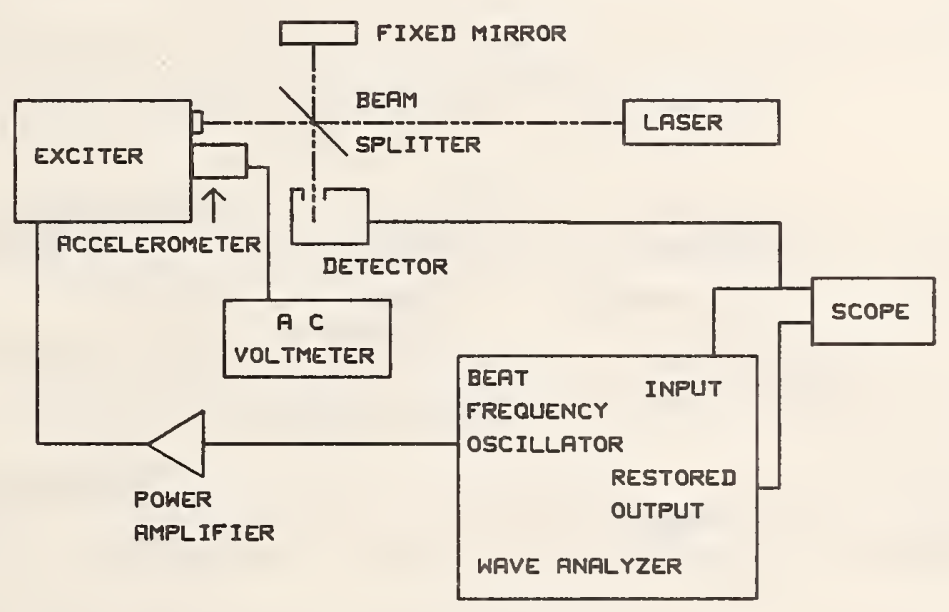

FIGURE 10. OPTICAL MEASUREMENT SYSTEM FOR 193 nm DISPLACEMENT

The filtered signal from the photodetector will go through nulls as the vibration amplitude is increased. The amplitude of the photocurrent follows the form [21]:

$$
I_{1}=2 B_{1}(4 \pi d / \lambda)
$$


where $J_{1}$ is the first-order Bessel function of the first kind, and the other symbols have the previously defined meanings.

At discrete amplitudes of vibration, corresponding to nulls of the $J_{1}$ Bessel function, the accelerometer output is measured by a digital voltmeter. The sensitivity is then calculated according to Eq. (9) above. The null points may be established by the wave analyzer, and are usually at least $60 \mathrm{~dB}$ below the maximum photodetector output signal. With the He-Ne light source, the first null occurs at $\mathrm{d}=192.96 \mathrm{~nm}$. Since the filtered output of the photodetector is a replica of the vibrational displacement, a phase calibration of the pick-up can readily be obtained with this set-up [22].

\subsection{Folded-Beam Interferometer}

The folded-beam interferometer is very similar to the Michelson interferometers described in the previous sections. Its purpose is to increase the resolution of the displacement measurement. For example, if the information-carrying beam of a fringe-counting interferometer is made to undergo seven folds, the double- amplitude displacement necessary for a dark-bright fringe change at the photodetector is only one-seventh of the normal $\lambda / 4$. The artifice of beam folding is not limited to any particular method of processing the information. It has also been applied to the method of Section 3.6 to maintain a more uniform test acceleration over a broad range of frequencies.

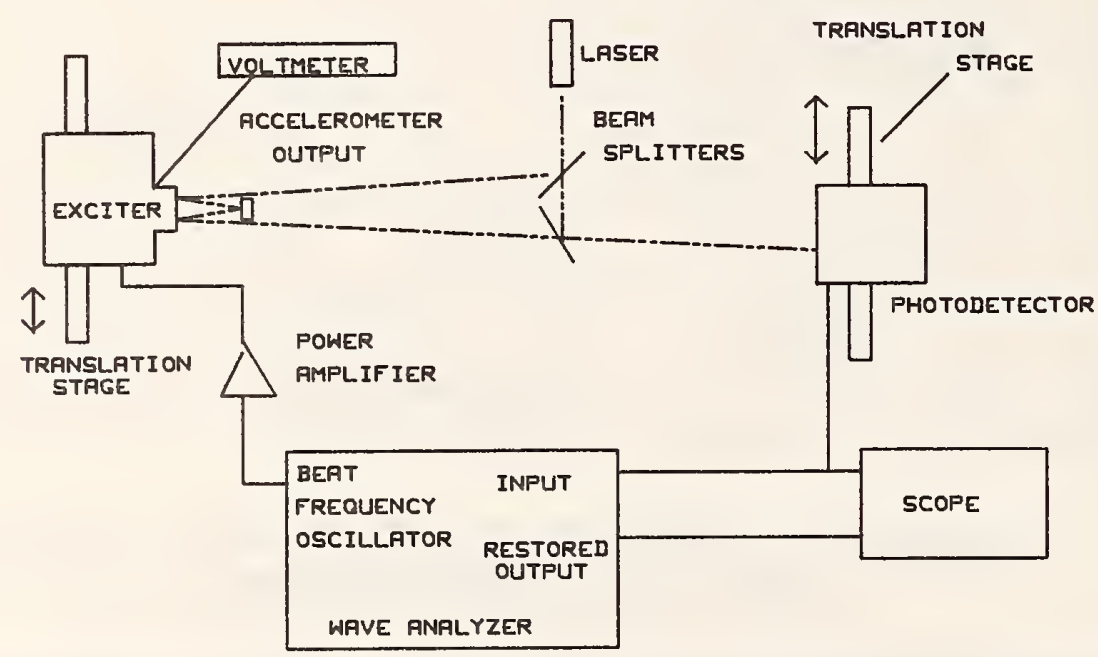

FIGURE 11. FOLDED BEAM INTERFEROMETER

A folded-beam configuration is shown in Fig. 11. The light from the laser source is split into two beams: a reference beam and a beam impinging on the 
mirror attached to the moving element of the vibration exciter. The latter beam then undergoes multiple reflections between this mirror and an adjustable one in front of the moving element. The number of such reflections (folds) depends on the distance and angle between the mirrors. The emerging beam then enters a second beam splitter where it recombines with the reference beam. The angle between the normal to the exciter top and the incident light beam must be small to minimize the error in the amplitude measurement. The error will be proportional to $(1-\cos \theta)$, where $\theta$ is the angle between the incident light and the normal. The apparatus is mounted on a granite isolation platform with air springs as isolators. This isolation from floor movement is required to improve the signal-to-noise ratio of the photodetector output.

\section{References}

1. IEEE Standard Dictionary of Electrical and Electronic Terms, p.1 (IEEE, Inc. New York 1977).

2. ISO/DIS 5347 Methods of Calibration of Vibration and Shock Pickups, distr. by American National Standards Institute, New York, (International Organization for Standardization, 1985).

3. National Bureau of Standards Calibration Service Users Guide,Nat. Bur. Stand. (U.S.), Spec. Publ. 250 (1986).

4. T. Dimoff and B. Payne, "Development and Calibration of NBS Vibration Shaker AF V," NBS Report 9670, January 1968.

5. B. F. Payne, and M. R. Serbyn, "Calibration of Accelerometers by Comparison with NBS Standards," NBS Technical Note (in preparation).

6. R. S. Koyanagi, "Development of a Low-Frequency Vibration Calibration System," Experimental Mechanics, 15, $443-448$ (1975).

7. T. Dimoff, "Electrodynamic Vibration Standard with Ceramic Moving Element,"J. Acoust. Soc. Amer. 40, 671 (1966).

8. E. Jones, W. B. Yelon, and S. E. Edelman, "Piezoelectric Shakers for Wide-Frequency Calibration of Vibration Pickups," J. Acoust. Soc. Amer. 45, 1556-1559 (1969).

9. B. F. Payne, "Absolute Calibration of Back-to-Back Accelerometers," Proc. ISA 27th Int.Instrumentation Symposium, Indianapolis, Ind. April 26-30, 1981.

10. B. F. Payne, "The Back-to-Back Accelerometer as a High Frequency 
Vibration Standard," Proc. ISA 31st Int. Instrumentation Symposium, San Diego, CA, May 6-9, 1985.

11. B. F. Payne, "The Application of Back-to-Back Accelerometers to Precision Vibration Measurements," J. Research NBS 88, 171-174, (1983).

12. American National Standard, "Methods for the Calibration of Shock and Vibration Pickups," S2.2-1959 (R1976), (American National Standards Institute, New York, NY).

13. S. Levy and R. R. Bouche, "Calibration of Vibration Pickups by the Reciprocity Method," J. Research NBS 57, $227-243$ (1956) RP2714.

14. R. R. Bouche and L. C. Ensor, "Use of Reciprocity Calibrated Accelerometer Standards for Performing Routine Laboratory Comparison Calibrations, "Shock and Vibration Bull., 34, Part 4, pp. 21-29, February 1965.

15. B. F. Payne, "Absolute Calibration of Vibration Generators with Timesharing Computer as Integral Part of System,"Shock and Vibration Bull, 36, Part 6, pp. 183-184, February 1967.

16. R. R. Bouche, Development of Standards for the Measurement of Vibratory Motion, Ph.D. Thesis, Department of Mechanical Engineering, University of Maryland, 1959.

17. R. R. Bouche, Calibration of Shock and Vibration Measuring Transducers (The Shock and Vibration Information Center, Washington, DC 1979).

18. B. F. Payne, and M. R. Serbyn, "An Automated System for the Absolute Measurement of Pickup Sensitivity," Nat. Conf. of Standards Laboratories 1983 Workshop and Symposium, Boulder, CO, July 18-21, 1983.

19. B. F. Payne, "Automation of Vibration Testing at the National Bureau of Standards,"Proc. IES 30th Annual Technical Meeting, Orlando, FL, May 1-3, 1984 (IES, Mt. Prospect, IL).

20. M. R. Serbyn, and W. B. Penzes, "A Real-Time Active Vibration Controller,"ISA Transactions, 21, 55-59 (1982).

21. V. A. Schmidt, S. Edelman, E. R. Smith, and E. Jones, "Optical Calibration of Vibration Pickups at Small Amplitudes," J. Acoust. Soc. Amer., 33, 748-751, (1961).

22. M. R. Serbyn and F. A. Andrews, "Measurement of the Phase of Vibrational Displacement by a Laser Interferometer," J. Acoust. Soc. Amer., 46, 2-5 (1969). 
NBS.114A (REV. 2-80)

U.S. DEPT. OF COMM.

BIBLIOGRAPHIC DATA

SHEET (See in structions)
1. PUBLICATION OR

REPORT NO.

iNBS/TN-1232
2. Performing Organ. Report Nof 3. Publication Date

Feb. 1987

4. TITLE AND SUBTITLE

A Description of NBS Calibration Services in Mechanical Vibration and Shock

5. AUTHOR(S)

D. C. Robinson, M. R. Serbyn, B. F. Payne

6. PERFORMING ORGANIZATION (If joint or other than NBS, see instructions)

7. Contract/Grant No.

NATIONAL BUREAU OF STANDARDS

DEPARTMEN T OF COMMERCE

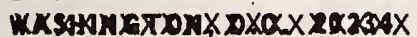

Gai thersburg, MD 20899

9. SPONSORING ORGANIZATION NAME AND COMPLETE ADDRESS (Street. CIIY, StOte, ZIP)

8. Type of Report \& Period Covered Fina

Same as item 6 .

10. SUPPLEMENTARY NOTES

Document describes a computer program; SF-185, FIPS Software Summary, is attached.

11. ABSTRACT (A 200-word or less factual summary of most significant information. If document includes a significant bibliography or literature survey, mention it here)

Accurate calibration of accelerometers requires that accurate measurement techniques be developed and maintained. Calibrations of vibration exciters and pickups are performed by comparison with the response characteristics of NBS standard accelerometer $\$$ or by absolute methods. This paper gives a summary of the various calibration procedures used in the calibration of accelerometers and reference exciters. The frequency ranges, vibration levels and accuracy statements for standardized tests designed to meet a variety of user needs are listed.

12. KEY WORDS (Six to twelve entries; alphabetical order; capitalize only proper names; and separate key words by semicolons) Absolute calibration; accelerometers; calibration services; comparison calibration; frequency ranges; interferometer; reciprocity method; reference exciter; shock calibration standard accelerometer; vibration measurements

\section{AVAILABILITY}

XX] Unlimited

For Official Distribution. Do Not Release to NTIS

XX Order From Superintendent of Documents, U.S. Government Printing Office, Washington, D.C. 20402.

Order From National Technical Information Service (NTIS), Springfield, VA. 2216I
14. NO. OF PRINTED PAGES 26

15. Price 



\section{Technical Publications}

\section{Periodical}

Journal of Research-The Journal of Research of the National Bureau of Standards reports NBS research and development in those disciplines of the physical and engineering sciences in which the Bureau is active. These include physics, chemistry, engineering, mathematics, and computer sciences. Papers cover a broad range of subjects, with major emphasis on measurement methodology and the basic technology underlying standardization. Also included from time to time are survey articles on topics closely related to the Bureau's technical and scientific programs. Issued six times a year.

\section{Nonperiodicals}

Monographs-Major contributions to the technical literature on various subjects related to the Bureau's scientific and technical activities.

Handbooks-Recommended codes of engineering and industrial practice (including safety codes) developed in cooperation with interested industries, professional organizations, and regulatory bodies.

Special Publications--Include proceedings of conferences sponsored by NBS, NBS annual reports, and other special publications appropriate to this grouping such as wall charts, pocket cards, and bibliographies.

Applied Mathematics Series-Mathematical tables, manuals, and studies of special interest to physicists, engineers, chemists, biologists, mathematicians, computer programmers, and others engaged in scientific and technical work.

National Standard Reference Data Series-Provides quantitative data on the physical and chemical properties of materials, compiled from the world's literature and critically evaluated. Developed under a worldwide program coordinated by NBS under the authority of the National Standard Data Act (Public Law 90-396).

NOTE: The Journal of Physical and Chemical Reference Data (JPCRD) is published quarterly for NBS by the American Chemical Society (ACS) and the American Institute of Physics (AIP). Subscriptions, reprints, and supplements are available from ACS, 1155 Sixteenth St., NW, Washington, DC 20056.

Building Science Series-Disseminates technical information developed at the Bureau on building materials, components, systems, and whole structures. The series presents research results, test methods, and performance criteria related to the structural and environmental functions and the durability and safety characteristics of building elements and systems.

Technical Notes-Studies or reports which are complete in themselves but restrictive in their treatment of a subject. Analogous to monographs but not so comprehensive in scope or definitive in treatment of the subject area. Often serve as a vehicle for final reports of work performed at NBS under the sponsorship of other government agencies.

Voluntary Product Standards-Developed under procedures published by the Department of Commerce in Part 10, Title 15, of the Code of Federal Regulations. The standards establish nationally recognized requirements for products, and provide all concerned interests with a basis for common understanding of the characteristics of the products. NBS administers this program as a supplement to the activities of the private sector standardizing organizations.

Consumer Information Series-Practical information, based on NBS research and experience, covering areas of interest to the consumer. Easily understandable language and illustrations provide useful background knowledge for shopping in today's technological marketplace.

Order the above NBS publications from: Superintendent of Documents, Government Printing Office, Washington, DC 20402.

Order the following NBS publications-FIPS and NBSIR's-from the National Technical Information Service, Springfield, VA 22161.

Federal Information Processing Standards Publications (FIPS PUB)-Publications in this series collectively constitute the Federal Information Processing Standards Register. The Register serves as the official source of information in the Federal Government regarding standards issued by NBS pursuant to the Federal Property and Administrative Services Act of 1949 as amended, Public Law 89-306 (79 Stat. 1127), and as implemented by Executive Order 11717 (38 FR 12315, dated May 11, 1973) and Part 6 of Title 15 CFR (Code of Federal Regulations).

NBS Interagency Reports (NBSIR)-A special series of interim or final reports on work performed by NBS for outside sponsors (both government and non-government). In general, initial distribution is handled by the sponsor; public distribution is by the National Technical Information Service, Springfield, VA 22161, in paper copy or microfiche form. 
U.S. Department of Commerce

National Bureau of Standards

Gaithersburg, MD 20899

Official Business

Penalty for Private Use $\$ 300$ 